\title{
THE ECONOMICS OF HILL COUNTRY DEVELOPMENT
}

\author{
J. S. HOLDEN \\ Farm Advisory Officer (Econ.), Department of \\ Agriculture, Palmerston North
}

THE Agricultural Development Conference has called for an enormous increase in agricultural investment of between $£ 400$ million and $£ 600$ million in the next eight to ten years. The magnitude of the planning problem is clear when it is realized that gross farm investment must reach about f45 million annually to reach the targets. This figure, suggested by Professor B. P. Philpott in 1963, is about double that achieved in the last few years.

There is known to be a very close relationship between farmers' disposable income and their rate of gross investment. Doubling the present rate of gross investment will have to occur without a prior doubling of disposable income. This leads to the inescapable conclusion that the industry must face structural changes, especially in the borrowing field. The whole concept of farm improvement based on development out of income with minimum recourse to borrowed capital must be forgotten. In fact, reorganization is necessary.

$£ 45$ million per year is a large sum, representing about $f 1$ per acre of farmable land, or f2 per acre of farmed land. Professor Philpott put the return on additional capital invested in agriculture as a whole at about 15 to $20 \%$. This appears better than any other investment available, but is based on some rather tenuous assumptions about the value of added investments. It must always be remembered that a structural change inevitably involves a change in costs and prices. Increased stocking means a shortage of replacement stock for sale, and a probable rise in their price. Slaughterings must initially decrease. Manufacturing and transport facilities are extended, with a change in their cost and price structure. The whole complex organization of agriculture must be adjusted, and without very tight controls (or good planning) elements of fluctuation and a consequent uncertainty must creep in.

The problem then is: Is hill country development a good avenue for investment; if so, how, in general, should it be 
done? If the questions can be answered, if only in a generalized way, some of the uncertainty induced by the necessary structural changes will be removed.

To help answer the question, a method of ranking alternative investments is required. With this, technological advances resulting from an increased research effort can be integrated with the real farm situation., and each new practice evaluated for its effect on the individual farmer.

This is a long way from the subject of hill country development profitability. But without an understanding of the importance of making the correct choice, the economics of this particular sector of agriculture cannot really be appreciated.

The Evaluation of Development Programmes

Briefly, there are two broad methods of investigating hill country development profitability. First, a generalized model of a development programme can be built up mathematically. After inserting the right data, the model could be used to indicate the sensitivity of profits to changes in any included variables.

Second, the case study approach can be used. There are two types of case study-an historical study, with known input and output data, or a forecast budget study, using expected input and output data. The former, called an ex-post study, is used in a project of the writer's; the latter, ex-ante, approach has been tried by other workers, notably A. Wright, at Massey University of Manawatu.

The real measure of the profitability of development is, very simply, profits themselves. But because of the singular characteristics of hill country development, these profits must be adjusted in several weys to allow comparison between different programmes. The relative delays before increased profits accrue are very important factors in development. The level of profits being earned before the programme commences must be brought into the calculation. A nother adjustment, in an historical approach, is made necessary because costs and prices may be different today compared with those occurring during the development. This last adjustment is done by a process called deflation, in which all receipts and payments are put on a common basis. In the present studies the basis is the 1962-3 cost and price level.

This process of deflation in historical case studies introduces an unfortunate air of unreality into the data. A 
farmer's decisions are to a very large extent governed by the costs and prices he is receiving at any given time. The process of deflating all historical data to a current level lifts the programme right out of its actual decision-making environment into an artificial economic climate. Nevertheless, the unreality is accepted, knowing that a study of fore cast budgets suffers the same disadvantage.

After these adjustments have been made, the programme's profitability can be calculated. This is done in these studies by calculating the "present value" of the programme. A formal definition of present value is "the sum of the annual discounted additional surpluses, the postdevelopment annual additional surplus being capitalized at the discount rate, then discounted and added to the sum". (See appendix.)

This can be explained more simply as follows. Assume the programme was put into operation today. The expected stream of added profits (or losses) is then adjusted to find its "present worth". If, in, say, the 10th year of the programme, an added profit of $£ 100$ was expected, the present worth of that $£ 100$ is about $£ 65$, if the acceptable borrowing' and lending rate was $6 \%$. That is, if today $£ 65$ is put in some security which returned 6\% compound interest, that $£ 65$ would grow to $£ 100$ in 10 years. The added profit in each and every year is similarly treated, including all the added profits for every year following development. of course, when one starts adjusting the expected profits in the 20th or 40th years, their present values become small, and unlikely to affect the answer. After each added profit has been adjusted to its "present worth", they are added together to give the present value of the programme as a whole. If the interest rate chosen is $6 \%$, and the present value comes to exactly zero, the programme returns just $6 \%$. If the present value is greater than zero, the return is greater than $6 \%$; put another way, the programme is profitable if $6 \%$ is considered an acceptable rate of interest on the capital. Conversely if the present value is negative, then the programme is unprofitable, at $6 \%$.

A nother way to look at the present value is as a windfall gain. Say the programme has a present value of $£ 2,000$. This means that if started today and completed, the equivalent of $£ 2,000$ is put into the farmer's hand, today. He is $£ 2,000$ better off before he does anything, because $£ 2,000$ repre sents the present value of all future additional expectations, as a lump sum. 
HILL COUNTRY DEVELOPMENT ECONOMICS

TABLE 1: HILL COUNTRY DEVELOPMENT. SOME "PRESENT VALUES"

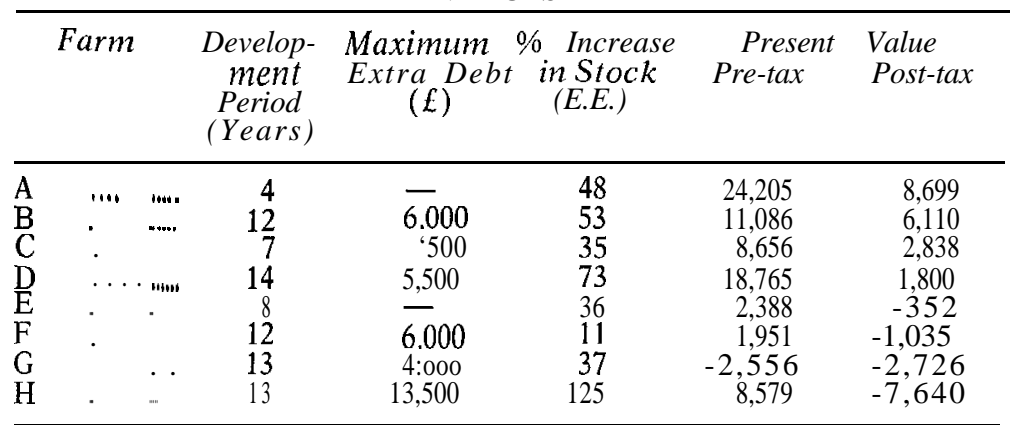

Maximum extra debt $=$ the maximum additional overdraft required to finance the programme.

$\%$ increase in stock $=$ difference between end and beginning ewe equivalents as a percentage of the beginning level.

Table 1 indicates the present value of some development programmes studied. Since all costs and prices are at 1962-3 levels, the present values are those operative in 1962-3 if an identical programme had started in that year, and expected costs and prices were those of that year. Some additional information on the programmes is included for the sake of clarity. These examples are not a representative sample of hill country farms, and are included as illustrations only. They, and several others (to be the subjects of a forthcoming bulletin from the Lincoln College Agricultural Economic Research Unit) are available because of a very fine gesture by the Meat and Wool Boards' Economic Service, which felt the problem of hill country development was so important that these cases should be made available on a confidential basis.

The comments in the rest of this paper are the results of a close study of 16 development programmes, and contact with another 15 . Since the basis of study is the case history, statistical vertification of comments is impossible. The comments are therefore based on impressions, with such generalizations as the data allow.

\section{The Dominant Factors Affecting Hill Country Development Economics}

Those factors have been chosen which appear to consistently affect profitability to the greatest degree. Other factors, of only minor importance, will be discussed later. 


\section{(1) Rate of Stock Increase}

Measured by an increase either in total ewe equivalents or in breeding stock, this factor completely dominates hill country economics. On the farms studied, the increases achieved in profitable programmes were consistently greater than those in other cases. The dividing line is somewhere in the region of 5 to $7 \%$ per annum. This finding is, on reflection, fairly obvious anyway. But a depressingly large number of farmers, even today, commence farm development and increase stock subsequently as they, or the money to purchase them, becomes available. In other words, their primary consideration is acres in grass, and stock on grass becomes secondary.

This clearly indicates that a reversal in planning procedures is required. All farmers and advisers, when contemplating development, should plan the stock picture first and tailor the development programme to it. In this way, the money invested in clearing, grassing and improvement becomes productive immediately.

A distinct possibility of a loss will always arise when development is continued with the aim of increasing per stock - unit production alone. This arises partly because the additional inputs required to raise wool weights per sheep are of an annual nature. For example, another 1 cwt of fertilizer per acre may be needed ; but it is needed every year, If, on the other hand, stock numbers were increased, the additional numbers needed are both self-perpetuating and much easier to control than the extra grass and extra grazing management required to achieve and maintain the extra production per sheep.

\section{(2) TAXATION}

The writer hesitates to include taxation under the heading of a dominant factor affecting hill country development economics. Certainly it has an effect on the take-home pay of the developing farmer, but only after the programme is finished, under today's tax laws. But the case histories studied show a remarkable tendency to be more profitable after tax, the greater the increase in taxation. That is, the most sensible attack on the problem of taxation is to forget it, forge ahead, and attain the maximum possible rate of stock increase. Of course this will increase taxation, but the case histories show clearly that this is a more profitable strategy than slowing down the rate of increase in order to minimize taxation payments themselves. 
Thus taxation is not likely to be a dominani factor affecting profitability itself. But unfortunately it i, still a factor affecting farmers' decisions about the protis they want to make. They are possibly too worried about ihe size of the cheque to the Inland Revenue Department, and forgetful of the rise in after-taxation profits. If so, and if farmers cannot be persuaded otherwise, then a suostantial rise in stock numbers will be achieved only if this psychological block is removed by raising the income it which maximum taxation rates apply. Colleagues at Lilcoln College are confident that national taxation revenud will be little affected by tampering with rates at the extreme end of the tax scale.

\section{(3) S PEED OF DEVELOPMENT}

There seems to be no clear relationship between the speed of development and profitability. That is, a farmer who rushes in and opens up an impressive amount of country in a short time will be successful only if his finances permit him to stock that country as heavily as possible, at the same time. The golden rule still applies: limit the increase in feed available to the mouths available.

\section{(4) Method of Financing Development}

This thorny problem crops up in all discussions and is quite simply answered. The method of evaluating profitability, as has been outlined, obviously takes account of the cost of borrowed capital. Whether development should be financed out of income, or by creating some risk and borrowing, is entirely up to the individual farmer and his willingness to undertake risks. Of course, the increase in take-home pay occurs earlier if the money is borrowed, simply because the job is likely to go faster. But careful planning and attention to the stocking situation will let any level of borrowing be profitable.

Thus the two rules of borrowing are:

(1) Increase stocking as fast as possible, within the labour limitation.

(2) Borrow, if necessary, to provide the money for development and stock to achieve this increase.

The only limit is the risk the farmer is willing to undertake. If he is correctly advised, and provided with plans, his uncertainty will be reduced, and the job accomplished more quickly because his subjective borrowing limit can be increased. 
(5) Method of Development

Far too many farmers worry about this problem. It is important, but only if no regard is paid to the stock available to eat the result of the development. First, there is no reason to suppose that because country is ploughable, the development method should include cultivation. If the country is ploughable, cultivation pays only if the stock will benefit from the winter feed crop, and if the extra mouths are available to fully utilize the new grass right from the start. Second, every district has its "best" method of producing new grass on its flat, or on its hilly country. For example, the dry Wairarapa, probably limited in its potential rate of stock increase, is more likely to be profitably developed without the tractor. But the wet King Country, with an immediate potential for stock increase, may also benefit more from development without the tractor. This is because the very nature of the King Country allows stocking with extra super-phosphate to achieve rapid increases. In other words the tractor is only useful if:

( 1) Rapid increases are possible, but only through cropping.

(2) If the weed problem is such that no method other than cultivation and cropping is going to combat it in reasonable time. (Gorse is one such weed.)

\section{(6) Labour Availability}

The case studies suggest that the effect of extra labour is second only to the problem of extra stock. Labour comes only in lumps and the problem arises when a decision has to be made about hiring the next lump, and building a house. From all that has been said so far, it will be clear that labour increases are justified only if the stock is available to pay for it.

The profitability of development will thus be increased if some way of increasing stock past the one-man level (say 1,500 to 1,600 ewes) without extra labour is used. For example, use a dry flock, or a Perendale flock, and stock the additional grass to capacity with these. If, at some later stage, an advantage can be seen in changing these stock to some more labour-demanding flock do so, but only if the extra labour is fully committed as soon as it arrives. That is, do not get another man at 1,200 ewes, and over the next 10 years build up to 2,000 ewes, The immediate cost of this man will far outweigh the long distant gains, 


\section{$O$ ther Factors Affecting the Profitability of D evelopment}

So far, no mention has been made of fertilizer rates, breeds or breeding programmes, stock potential, cost of fertilizer, and so on. These factors are unimportant in most hill country development programmes. Of course, the initial fertilizer application may need careful consideration, but thereafter the minimum rate required to maintain the much increased stock will rarely be above 3 cwt per acre. One extra ewe per acre will pay for another $4 \mathrm{cwt}$ and the margin is big enough for individual farmer preference to take over. If he feels $3 \mathrm{cwt}$ is needed, but the recommendation is $2 \mathrm{cwt}$, then another $1 / 4$ of a ewe equivalent will pay for it.

The rest of these secondary factors should be regarded as marginal. For example, substantial stock increases can be achieved only at the expense of a detailed flock improvement programme. This improvement can take place most profitably after development, unless of course, the present standard is so low that the sheep cannot stand the hard grazing required by most development programmes. People like J. Inglis have literally lifted the lid off old stocking potential ideas, even at low fertilizer rates. On the majority of farms, stocking is possibly limited more by a farmer's unwillingness to borrow, or pay higher wages for more labour at the right time, than it is by physical incapacity of the soil type.

\section{Conclusion}

This paper may well have given the impression that making development pay is a simple task. This is not its intention. Rather, it is an attempt to show that the economics of development depend largely on one or two dominant factors. What are minor considerations in the writer's view, are nowadays the major ones to other people.

The difficulty arises in planning. None of the conclusions arrived at can be implemented by rushing out and buying more sheep. They can be implemented only by very careful, detailed planning of future steps, with a correct evaluation of the economic impact of each step. The Department of Agriculture is willing to undertake this planning within the limits of its staffing. It is suggested that farmers contemplating further development consult an adviser and, with him, incorporate these ideas into a development plan which first shows possible stock increases year by year, and secondly provides sufficient feed for this stock. 
Finally, in answer to the question raised at the beginning of the paper, that of the advisability of diverting some of the nation's resources into hill country development, casestudies have shown that, providing the latest technological advances are incorporated in the programme, and providing the emphasis is on stock, the development of hill country is profitable, to the nation and the farmer.

\section{APPENDIX}

\section{The Present Value Criterion}

Present value of the development programme is defined as the sum of the annual discounted additional surpluses (defined below), the final annual additional surplus being capitalized at the discount rate, then discounted and added to the sum.

Additional surplus is defined as the amount over or under a "predevelopment surplus", occurring in each year of the development programme and thereafter. "Surplus" is the difference between total cash receipts and total expenditure, excluding interest, depreciation, rent and taxation and including acquisition and salvage costs of all plant and implements, in the year in which such costs occurred.

Pre-development surplus is the surplus (defined above) which would occur year in and year out if no development programme had been undertaken. Due regard is paid to pasture maintenance costs, fencing costs (to maintain them at their pre-development standard), weed and pest control costs, and any other maintenance costs necessary to ensure constancy in this quantity.

The surplus following development (the "post-development surplus") is similarly defined, having the same regard to short and long term maintenance costs to ensure constancy of this quantity into the future, following development.

If $\mathbf{P}=$ present value of the development programme, then:

$$
\mathrm{P}=\sum_{\mathrm{i}=1}^{k} \frac{\left.\left(S_{\mathrm{i}}-S\right)+{ }^{+}{ }^{(} S_{\mathrm{n}}-S\right)}{(1+r)^{\mathrm{i}}} \quad r \quad \frac{1}{(1+r)^{\mathrm{k}}}
$$

Where $\mathrm{S}=$ pre development surplus

$$
S_{i}=\text { surplus in year } \mathbf{i}
$$

$S_{n}=$ post-development surplus

$\mathrm{i}=1,2, \ldots \mathrm{k}$

k being the "development" period

$\Sigma=$ "the sum of . .."

and $r=$ the discount rate (\%). 


\section{DISCUSSION}

If $a$ farmer develops using borrowed capital, he repays that capital out of taxable income; if he develops out of income, his taxable profits after development have no further calls on them.

Development expenditure using borrowed money is tax-deductible, and is thus almost equivalent to spending tax-deductible surplus income later on. The fact that repayments of borrowed money must be made from taxed profits in the future is not necessarily an indictment of the taxation policy, but of thc terms of repayment of the loan.

It is hoped thut the amount of work underlying the production of a table such as Table 1 is appreciated.

Since $1962-3$ costs and prices were used, were these matched by the inclusion of tux rates and concessions available at that time, and has Mr Holden included the effects of death duties in the evaluation?

1962-3 taxation rates were used. The only concessions included are those relating to extensions of deductible items of development expenditure. Other concessions can easily be included, but they are mostly specific in their applications, i.e., they cannot be evaluated for the general farm situation. Death duties have not been included, because I have been dealing with productive valuations, not probate valuations, in assessing the increases in capital due to development. The evaluation can be easily adjusted to explore death duty impositions.

Did $M r$ Holden imply that speed of development did not affect profitability?

No. I stated that there was no clear relationship between speed of development and profitability. But if speed of development is measured-in terms of-stock increases, together with a feed increase programme just matching stock increases, then there is a clear relationship.

Was the increase in capital value due to development taken into account in the calculation?

Yes. but not the increase in fair sale value. While of interest. the increase in sale value is difficult to assess, especially in the future. But the minimum market value which must be received following development, if the programme is to be profitable, can be inferred from the calculations.

There is clearly a difference betwen a 2-year and a 10 -year develop ment programme. Was this difference taken into account?

Yes, by the process of discounting. This makes allowance for profits accruing following a 2-year programmc to be of greater value at present than thosc foilowing a lO-year programme.

Farmers who have had an increase in stock numbers are not necessarily those who have undergone a development programme. How did the speaker ensure that his farms were $a$ fair cross-section-'of development farms? 
Using case-history methods, and with the extreme shortage of good data on development, a good cross-section is impossible to achieve, as was stated in the paper. But the Meat and Wool Board's sample of hill country farms is random itself; my cases were chosen from within this sample by referring to development expenditure. If an increase in this itcm had occurred, the case was chosen. From the rcsulting list, the final list was formed by referring to likely farmer co-operation, ownership changes, and so on.

Would a rise in cost of replacement stock hold up development?

Within the limits imposed by the farmer's available cash, yes. It is quite conceivable that the increases called for in the next 10 years will have this effect, in which case development of hill country in general will have to be re-evaluated.

How do farmers determine the priorities of, and the relative ex. penditures on, for example, fencing and topdressing?

I wouldn't hazard a guess. But my proposed scheme of planning a development programme based on the planning of stock increases and matching development expenditure to thosc increases automatically sorts out priorities.

How many extra ewes would a farmer need to puy for an extra man and his housing?

This depends on the present level of production, and the economic efficiency of that production. But certainly 1,000 ewes is a minimum to just break even.

Does Mr Holden think a farmer al a good living standard has enough incentive to increase his production?

If he is satisfied, completely, then clearly the answer is no. Judging from many farmers' comments in journals, newspapers and so on, however, this is not the case. 